\title{
Coarse, but not finely ground, dietary fibre increases intestinal Firmicutes:Bacteroidetes ratio and reduces diarrhoea induced by experimental infection in piglets
}

\author{
Francesc Molist ${ }^{1 *}$, Edgar Garcia Manzanilla ${ }^{2}$, José Francisco Pérez ${ }^{1}$ and Charles Martin Nyachoti ${ }^{3}$ \\ ${ }^{1}$ Departament de Ciència Animal i dels Aliments, Universitat Autònoma de Barcelona, O8193, Bellaterra, Spain \\ ${ }^{2}$ Department of Animal Science, University of California, Davis, CA 95616, USA \\ ${ }^{3}$ Department of Animal Science, University of Manitoba, Winnipeg, Manitoba, Canada R3T2N2 \\ (Submitted 15 February 2011 - Final revision received 16 June 2011 - Accepted 23 August 2011 - First published online 29 September 2011)
}

\section{Abstract}

Using dietary fibre to control childhood diarrhoea has rarely been discussed. However, dietary fibre is being proposed to prevent diarrhoea in piglets. The present study aimed to study the effects of introducing fibre in the post-weaning piglet diet and its particle size on the intestinal ecosystem before and after an experimental infection with Escherichia coli. A total of thirty-six post-weaning piglets were assigned to four experimental diets: a negative control (NC) diet, the same diet with $4 \%$ wheat bran coarse (WBC) particle size or finely milled (WBF) and a positive control (PC) diet with an antibiotic. On day 9, animals were challenged with E. coli. Faecal and digesta samples were obtained before and after the experimental infection and changes in the microbial ecosystem were measured. Animals fed the WBC and the PC diets showed a significant reduction in the faecal score compared with the NC diet. The inclusion of WBc in the diet increased total volatile fatty acid concentration, reduced Bacteroidetes in the faeces before and after the experimental infection compared with the $\mathrm{NC}$ diet and increased Firmicutes at the end of the experiment. Based on the results, diarrhoea scours and the composition of the pig gut microbial community are modified by the inclusion of a relatively small amount of wheat bran in the diet, being the physical presentation of the fibre a determinant of that difference.

\section{Key words: Post-weaning diarrhoea: Microbiota: Intestinal health}

The gastrointestinal tract (GIT) is one of the most densely populated microbial habitats with densities in the colon up to $10^{12}$ cells $/ \mathrm{ml}$. Thus, bacterial cells within the GIT outnumber host cells by 10:1 and play key roles in the GIT function and development $^{(1-3)}$, and in the modulation of immune response $\mathrm{e}^{(4)}$. Unfortunately, most bacterial species present in the GIT, as well as their role in a healthy state, remain uncharacterised.

Imbalances in GIT microbiota may contribute to human and animal digestive disorders. Some of these disorders are clearly recognised as acute infections associated with the presence of specific bacterial species such as enterotoxigenic Escherichia coli (ETEC), which is the main cause of diarrhoea morbidity and mortality in humans and animals. Human cases of ETEC diarrhoea are more frequent in critical periods, such as the neonatal period ${ }^{(5)}$ or when breast-feeding cannot be maintained for the first 4-6 months of $\operatorname{life}^{(6)}$. A similar situation is observed in pig farms where early weaning results in high morbidity and mortality due to ETEC diarrhoea. This is considered to be one of the most economically important diseases in swine husbandry ${ }^{(7)}$

In childhood diarrhoea, oral rehydration solution and zinc are the only two treatments recommended so far by the WHO and $\mathrm{UNICEF}^{(8)}$. In the case of piglets, oral rehydration solution is too expensive to be used, and zinc is widely used. However, its use has raised some environmental concerns. Thus, new strategies need to be developed to prevent diarrhoea in piglets. These strategies may be considered as interesting treatments for human cases too.

Using dietary fibre to prevent and/or control childhood diarrhoea has rarely been discussed. However, dietary fibre is being proposed as a successful approach to prevent or treat diarrhoeal diseases in piglets ${ }^{(9)}$. Mateos et $a l^{(10)}$ suggested the need for a minimum content of dietary fibre in pig diets to reduce intestinal disorders; and we confirmed that wheat bran (WB) in the diet reduces enterobacteria and E. coli counts in the intestinal digesta and faeces of piglets ${ }^{(11)}$.

Abbreviations: ETEC, enterotoxigenic Escherichia coli; FS, faecal score; GIT, gastrointestinal tract; NC, negative control; PC, positive control; TRF, terminal restriction fragments; t-RFLP, terminal restriction fragment length polymorphism; VFA, volatile fatty acids; WB, wheat bran; WBc, wheat bran coarse; WBf, wheat bran finely milled; WRC, water retention capacity. 
We hypothesised that WB as a fibre source has a preventive effect on $E$. coli diarrhoea and this effect depends on its physical presentation. Thus, in the present study, we investigated the effects of a dietary intervention with WB (either as coarse (WBc) or finely (WBf) ground particle size) on the intestinal microbial communities before and after an experimental infection with an ETEC K88 ${ }^{+}$.

\section{Materials and methods}

\section{Animals, housing, experimental design and experimental} diets

The experimental protocol (permit no. F04-028/1/2/3) was reviewed and approved by the University of Manitoba Animal Care Committee and pigs were cared for according to the guidelines of the Canadian Council on Animal Care ${ }^{(12)}$. A total of thirty-six Genesus ((Yorkshire $\times$ Landrace $) \times$ Duroc) piglets weaned at $17 \pm 1$ days of age were obtained from the University of Manitoba's Glenlea Swine unit. Pigs were weighed, individually housed and randomly assigned to one of four experimental diets by littermate and sex. Experimental diets (Table 1): a negative control (NC) diet based on maize, wheat, barley and soyabean meal; the NC diet with $4 \%$ WB as coarse $(1088 \mu \mathrm{m})$ particle size (WBc) or finely $(445 \mu \mathrm{m})$ milled (WBf); and the NC diet plus a feed antibiotic mix as positive control (PC). The antibiotic mix supplied per $\mathrm{kg}$ of diet: $110 \mathrm{mg}$ of chlortetracycline, $55 \mathrm{mg}$ of penicillin (as penicillin $\mathrm{G}$ Procaine) and $100 \mathrm{mg}$ of sulfamethazine (ASP-250; Alpharma, Fort Lee, NJ, USA). All experimental diets were formulated to meet the National Research Council ${ }^{(13)}$ nutrient requirements for piglets weighing $7-12 \mathrm{~kg}$ (digestible energy, $3400 \mathrm{kcal} / \mathrm{kg}$ (14235 kJ/kg); crude protein, 20.9\%; lysine, 1.2\%). The animals were housed in a Biohazard Level-2 animal facility that restricted access to unauthorised personnel, and all individuals using the facility were trained in procedures related to biohazard containment. Animals had unlimited access to feed and water throughout the 2 -week study period, with the room temperature set at $29 \pm 1{ }^{\circ} \mathrm{C}$.

\section{Experimental procedures and sampling}

Animals received the dietary treatments from day 1 to day 16 after weaning. On day 9, animals were assessed for diarrhoea in order to make sure that less than $5 \%$ of the animals were suffering from diarrhoea and faecal samples for microbial analysis were taken and immediately frozen at $-80^{\circ} \mathrm{C}$ for analysing the microbial structure by terminal restriction fragment length polymorphism (t-RFLP). Then, piglets received $6 \mathrm{ml}$ of a freshly prepared $E$. coli $\mathrm{K}_{8} 8^{+}$inoculum $\left(2 \cdot 2 \times 10^{10}\right.$ colony-forming units $\left./ \mathrm{ml}\right)$ following the procedure described by Bhandari et al. ${ }^{(14)}$. Health status of the animals and the severity of diarrhoea were assessed using the faecal consistency scoring method of Marquardt et al. ${ }^{(15)}$. E. coli challenge was considered successful if at least $90 \%$ of the animals in the NC group showed a faecal score (FS) of 1 or higher. On day 16 after weaning, animals were euthanised with an intravenous injection of sodium pentobarbital
Table 1. Composition and chemical analysis of pre-starter diets

\begin{tabular}{|c|c|c|c|c|}
\hline & \multicolumn{4}{|c|}{ Diets } \\
\hline & NC & PC & WBf & WBc \\
\hline \multicolumn{5}{|l|}{ Ingredients (g/kg DM) } \\
\hline Maize & 317.9 & $317 \cdot 8$ & $279 \cdot 4$ & $279 \cdot 4$ \\
\hline Wheat Canada & $200 \cdot 0$ & $200 \cdot 0$ & $200 \cdot 0$ & $200 \cdot 0$ \\
\hline Barley & $170 \cdot 0$ & $170 \cdot 0$ & $170 \cdot 0$ & $170 \cdot 0$ \\
\hline Soyabean meal, $44 \%$ CP & $136 \cdot 5$ & $136 \cdot 5$ & $130 \cdot 0$ & $130 \cdot 0$ \\
\hline Fish meal & $60 \cdot 0$ & $60 \cdot 0$ & $60 \cdot 0$ & $60 \cdot 0$ \\
\hline Dried whey, $12.27 \%$ CP & $45 \cdot 0$ & $45 \cdot 0$ & $45 \cdot 0$ & $45 \cdot 0$ \\
\hline Wheat bran & - & - & $40 \cdot 0$ & $40 \cdot 0$ \\
\hline $\begin{array}{l}\text { Spray-dried blood plasma, } \\
\text { NRC } 98\end{array}$ & $35 \cdot 0$ & $35 \cdot 0$ & $35 \cdot 0$ & $35 \cdot 0$ \\
\hline Vegetable oil & $15 \cdot 0$ & $15 \cdot 0$ & $20 \cdot 0$ & $20 \cdot 0$ \\
\hline Calcium carbonate & $5 \cdot 8$ & $5 \cdot 8$ & $5 \cdot 8$ & $5 \cdot 8$ \\
\hline Dicalcium phosphate & 3.3 & 3.3 & 3.3 & 3.3 \\
\hline Vitamin premix ${ }^{*}$ & $5 \cdot 0$ & $5 \cdot 0$ & $5 \cdot 0$ & $5 \cdot 0$ \\
\hline Mineral premix $\dagger$ & $5 \cdot 0$ & $5 \cdot 0$ & $5 \cdot 0$ & 5.0 \\
\hline Antibioticsł & - & 0.1 & - & - \\
\hline \multicolumn{5}{|l|}{ Chemical analysis ( $/ \mathrm{kg} \mathrm{DM}) \S$} \\
\hline DM & $899 \cdot 0$ & $899 \cdot 0$ & $905 \cdot 0$ & $904 \cdot 0$ \\
\hline Ash & 58.9 & $57 \cdot 8$ & 57.5 & 63.4 \\
\hline GE (MJ/kg DM) & $19 \cdot 0$ & 18.9 & $19 \cdot 0$ & $19 \cdot 0$ \\
\hline Diethyl ether extract & $45 \cdot 2$ & $45 \cdot 3$ & $50 \cdot 8$ & $51 \cdot 8$ \\
\hline $\mathrm{CP}$ & 241.0 & $239 \cdot 0$ & 241.0 & $240 \cdot 0$ \\
\hline NDF & 144.9 & $147 \cdot 0$ & $159 \cdot 5$ & $159 \cdot 5$ \\
\hline ADF & 34.0 & 34.7 & 37.8 & 37.8 \\
\hline Starch & 458.8 & $459 \cdot 7$ & 435.7 & $430 \cdot 4$ \\
\hline Particle size $(\mu \mathrm{m})$ & $559 \cdot 0$ & $558 \cdot 0$ & 564.0 & $586 \cdot 0$ \\
\hline
\end{tabular}

$\mathrm{NC}$, negative control; $\mathrm{PC}$, positive control; WBf, wheat bran milled; WBc, wheat bran coarse; CP, crude protein; NRC, National Research Council; GE, gross energy; NDF, neutral-detergent fibre; ADF, acid-detergent fibre.

* Provided per $\mathrm{kg}$ of diet: $18 \mathrm{mg}$ copper, $110 \mathrm{mg}$ zinc, $0.2 \mathrm{mg}$ iodine, $110 \mathrm{mg}$ iron, $50 \mathrm{mg}$ manganese and $0.3 \mathrm{mg}$ selenium (FeedRite, A Division of Ridley Incorporation, Winnipeg, Manitoba, Canada)

† Provided per kg of diet: $20000 \mathrm{IU}(6000 \mu \mathrm{g})$ of vitamin A; $3200 \mathrm{IU}(80 \mu \mathrm{g})$ of vitamin $\mathrm{D} ; 120000 \mathrm{IU}(79920 \mu \mathrm{g})$ of vitamin $\mathrm{E} ; 7000 \mathrm{mg}$ of vitamin $\mathrm{K} ; 70 \mathrm{mg}$ of vitamin $\mathrm{B}_{12}$; $200 \mathrm{mg}$ of folic acid; $120000 \mathrm{mg}$ of pantothenic acid; $4000 \mathrm{mg}$ of pyridoxine; $16000 \mathrm{mg}$ of riboflavin; $3000 \mathrm{mg}$ of thiamine (FeedRite, A Division of Ridley Incorporation).

$\ddagger$ ASP-250; supplied per $\mathrm{kg}$ of diet: $110 \mathrm{mg}$ of chlortetracycline, $55 \mathrm{mg}$ of penicillin and $100 \mathrm{mg}$ of sulfamethazined (Alpharma Incorporation, Fort Lee, NJ, USA).

$\S$ All diets were formulated to contain $1.2 \%$ of Lys, but it was not analysed.

( $50 \mathrm{mg} / \mathrm{kg}$ body weight). Piglets were bled, and the abdomen was immediately opened. Empty weights of the stomach, the segments of the small intestine, caecum, colon, rectum, liver and spleen were recorded. Digesta samples were taken from the colon, pH was measured (AB 15; Fisher Scientific, Pittsburg, PA, USA) and $1 \mathrm{~g}$ subsamples were placed in sterile containers before transportation to the laboratory for microbial analysis. The remaining digesta was immediately frozen at $-80^{\circ} \mathrm{C}$ for determining ammonia-nitrogen concentration, volatile fatty acids (VFA) and analysing the microbial structure by t-RFLP.

\section{Analytical procedures}

Chemical analyses of the diets (Table 1) were performed according to the Association of Official Analytical Chemists ${ }^{(16)}$ standard procedures. Crude protein was quantified by a Leco NS 2000 Nitrogen Analyzer (Leco Corporation, St Joseph, MI, USA). Gross energy was measured with a Parr adiabatic oxygen bomb calorimeter (Parr Instrument Company, Moline, IL, USA). The E. coli concentration in the colon digesta was determined following the method described by Krause et al. ${ }^{(17)}$. 
The VFA determination was done by GC as described by Erwin et $a l .{ }^{(18)}$. Ammonia-nitrogen concentration was measured by the indole-phenol blue method ${ }^{(19)}$. The extraction of DNA from colon digesta and faeces was done using the QIAamp DNA stool Mini Kit (Qiagen, Valencia, CA, USA) with the modifications described by Bhandari et al. ${ }^{(14)}$. The t-RFLP analysis was used to assess changes in the microbial composition in the gut ${ }^{(20)}$. Primers 27 forward $\left(5^{\prime}\right.$ GAAGAGTTTGATCATGGCTCAG $3^{\prime}$ ) and 342 reverse (5' CTGCTGCCTCCCGTAG $3^{\prime}$ ) were used in order to amplify an informative sequence of the $16 \mathrm{~S}$ rRNA gene ${ }^{(21)}$. PCR conditions were as described by Bhandari et $a l .{ }^{(14)}$. To produce terminal restriction fragments, the bp 27-342 region of the 16S rRNA gene was digested using $\mathrm{HhaI}^{(14)}$. Microbial community analysis ${ }^{(22)}$ web services were used to build a putative reference database (called H.Q. database) of probable terminal restriction fragments of the gut. The fragment profiles produced by HhaI restriction of the bp $27-42$ product were applied to the H.Q. database in silico so that a reference library for this study could be constructed and exported to the phylogenetic assignment tool ${ }^{(23)}$. Concurrently, using t-RFLP data obtained from CEQ software (Beckman Coulter Inc., Brea, CA, USA) (fragment sizes and peak area), various profiles of interest were developed with reference to treatment. These libraries were entered into the hierarchical browser of the ribosomal database project ${ }^{(24)}$ and converted to GenBank format. The obtained libraries were then assigned to the library comparison tool of ribosomal database project-II.

On the other hand, the richness and diversity indices were calculated using Estimates $7.5^{(25)}$. An upper abundance limit of 5 was used to determine rare or infrequent species. The order of the samples was randomised 500 times for each run to reduce the effect of the sample order.

\section{Statistical analyses}

All data except for FS and microbial lineages from t-RFLP profiling were subjected to ANOVA, with dietary treatment as the classification factor, using the generalised linear model procedure ${ }^{(26)}$. FS was subjected to repeated measures using the mixed procedure ${ }^{(26)}$. For these analyses, multiple mean comparisons were done using Tukey's correction, 'animal' was considered the experimental unit $(n 9)$ and $\alpha$ level for determination of significance was 0.05 with tendencies for $0.05<P<0.15$ also reported. For the microbial lineages from t-RFLP profiling main factor $P$-values are not considered and least significant difference multiple-comparison test is directly used to calculate the statistical significance with an $\alpha$ level of $0 \cdot 01$.

\section{Results}

Animals were controlled during the experimental period for general health status and no excessive weight loss or deaths were registered for any of the animal.

\section{Organ weight (data not shown in tables)}

Stomach, small intestine, caecum, rectum and liver showed no significant weight differences among dietary treatments. However, the WBc diet increased colon empty weight, compared to the NC diet $(112 \cdot 8,120 \cdot 1,116 \cdot 2$ and $132 \cdot 0 \mathrm{~g}$ for $\mathrm{NC}$, $\mathrm{PC}, \mathrm{WBf}$ and $\mathrm{WBC}$ diets, respectively; $P=0.05)$. On the other hand, spleen weight tended to be lower in the PC diet compared to the $\mathrm{NC}$ diet at the end of the experimental period (29.1, 22.1, 24.6 and 23.1 g, for NC, PC, WBf and WBc diets, respectively; $P=0.077$ ).

\section{Microbial activity, diarrhoea scours and Escherichia coli population}

FS, E. coli population and VFA concentration in colon digesta on day 16 post-weaning are presented in Table 2. All animals had a FS of 0 just before they were challenged (day 9). After the inoculation with $E$. coli, all groups showed an increase in FS, but animals showed a different evolution of FS depending on dietary treatment. All animals fed the NC diet were affected by diarrhoea, whereas those fed the WBC and PC diets showed lower mean FS than the NC diet $(P<0.001$ in both cases). No differences were found in the VFA concentration in the faeces on day 9 post-weaning (averaging 156 , 92, 28, 25 and $11 \mathrm{mg} / 1$ for the total, acetic acid, propionic

Table 2. Experimental results for faecal score, Escherichia coli and volatile fatty acids (VFA) on day 16 of the experiment (Mean values with their standard errors, $n$ 9)

\begin{tabular}{|c|c|c|c|c|c|c|}
\hline \multirow[b]{2}{*}{ Item } & \multicolumn{4}{|c|}{ Diets } & \multirow[b]{2}{*}{ SEM } & \multirow[b]{2}{*}{$P$} \\
\hline & NC & $\mathrm{PC}$ & WBf & WBc & & \\
\hline Faecal score* & $1.5^{\mathrm{a}}$ & $0.5^{b}$ & $1 \cdot 1^{\mathrm{a}, \mathrm{b}}$ & $0.6^{\mathrm{b}}$ & 0.13 & 0.001 \\
\hline $\begin{array}{l}\text { E. coli (log cfu/g digesta) } \\
\text { VFA concentration (ma/l) }\end{array}$ & $7 \cdot 7$ & $7 \cdot 2$ & $7 \cdot 5$ & $5 \cdot 3$ & $2 \cdot 04$ & $0 \cdot 150$ \\
\hline Total & $255^{\mathrm{b}}$ & $300^{\mathrm{b}}$ & $253^{b}$ & $351^{a}$ & $76 \cdot 5$ & 0.041 \\
\hline Acetic acid & $155^{\mathrm{b}}$ & $156^{\mathrm{b}}$ & $135^{\mathrm{b}}$ & $193^{a}$ & $26 \cdot 2$ & 0.002 \\
\hline Propionic acid & 62 & 70 & 63 & 81 & $18 \cdot 1$ & 0.222 \\
\hline Butyric acid & 33 & 35 & 28 & 35 & $11 \cdot 2$ & 0.654 \\
\hline Isoacids & $5 \cdot 0$ & 4.0 & $6 \cdot 0$ & $7 \cdot 0$ & $2 \cdot 6$ & 0.145 \\
\hline
\end{tabular}

NC, negative control; PC, positive control; WBf, wheat bran milled; WBc, wheat bran coarse; cfu, colony-forming units.

${ }^{a, b}$ Mean values within a row with unlike superscript letters were significantly different $(P<0.05)$.

*Faecal score: 0 , normal; 1, soft faeces; 2 , mild diarrhoea; 3, severe diarrhoea. 
acid, butyric acid and isoacids concentration, respectively). In contrast, the inclusion of $\mathrm{WBC}$ in the diet increased the total concentration of VFA and the concentration of acetic acid in colon digesta, compared with the other diets on day 16. No differences were found in colon $\mathrm{pH}$ or ammonia concentration (60 and $205 \mathrm{mg} / \mathrm{l}$, respectively) at the end of the experiment.

\section{Microbial analysis by terminal restriction fragment length polymorphism}

Microbial analysis conducted using t-RFLP, generated profiles based on 16S rRNA fragments followed by HhaI enzyme digestion yielding different profiles among treatments, which could be differentiated taxonomically in the faeces on day 9 post-weaning and in colon digesta at the end of the experiment (Table 3). Based on the classification results, the majority of sequences were assigned to four phyla: Firmicutes $(63 \%$ of all sequences), Bacteroidetes (31\%), Proteobacteria (5\%) and Actinobacteria (0.9\%). On day 9 post-weaning, just before the experimental infection, significant differences were found in the Bacteroidetes, and more specifically, in the Bacteroidales order, where the inclusion of $\mathrm{WBC}$ in the diet reduced this bacterial population, compared with the NC diet $(P<0 \cdot 01)$. Quantitative but not significant changes were found also on the Firmicutes where the inclusion of $\mathrm{WBC}$ in the diet increased the proportion, compared with the NC diet. Differences were also found in colonic digesta on day 16, 7 days after the experimental infection with $E$. coli. Inclusion of WBC in the post-weaning diet increased the Firmicutes, and within this phylum the Clostridiales order, compared with the NC diet $(P<0 \cdot 01)$. At the same time, and similar to the results observed before the experimental infection with
E. coli, animals fed the WBc diet showed a lower proportion of Bacteroidetes and more specifically the Bacteroidales order, compared with the NC diet $(P<0 \cdot 01)$. No significant differences were found in the other phyla or classes of bacteria studied (data not shown). Differences between data from sampling days 9 to 16 could be due to the different location sampled each day or to the experimental infection applied to the animals. Thus, it should be noted that the effects of age and/or GIT location are out of the scope of the present experiment. We also investigated the effects of WB inclusion and particle size on a number of diversity indices. Estimates of diversity and richness are shown in Table 4. The WBc-fed animals had lower richness compared with the WBf diet and lower diversity compared with any other diet in the microbiota of the faeces on day 9 post-weaning. At the end of the experiment, animals fed the WBf diet showed the highest richness $(P<0.0001)$ and diversity $(P<0.0003)$ indexes in the microbiota of the colon, compared with the other three experimental diets. The WBC and PC diets reduced the richness of the microbiota of the colon digesta, compared with the NC diet $(P<0 \cdot 0001)$.

\section{Discussion}

The present experiment evaluated how fibre affects hindgut microbiota and its fermentative activity before and after a bacterial ETEC infection challenge. Main results showed changes in hindgut microbiota due to the coarse fibre included in the diet, which were associated with lower diarrhoea.

Challenging animals with a pathogenic E. coli K88 resulted in a controlled diarrhoea episode. Post-weaning collibacilosis is associated with serotypes that carry F4 or F18 fimbriae and

Table 3. Hierarchical bacterial composition of the faeces and of the colon digesta of nursery pigs before (day 9) and after (day 16) the challenge with enterotoxigenic Escherichia coli K88, based on terminal restriction fragment length polymorphism analysis

(Mean values with their standard errors, $n$ 9)

\begin{tabular}{|c|c|c|c|c|c|}
\hline \multirow[b]{2}{*}{ Taxon } & \multicolumn{4}{|c|}{ Microbial level (\%) } & \multirow[b]{2}{*}{ SEM } \\
\hline & $\mathrm{NC}$ & $\mathrm{PC}$ & WBf & WBc & \\
\hline \multicolumn{6}{|l|}{ Day 9} \\
\hline Phylum Firmicutes & $59 \cdot 1$ & $66 \cdot 3$ & $67 \cdot 9$ & $70 \cdot 1$ & $2 \cdot 38$ \\
\hline Class Clostridia & $56 \cdot 8$ & 64.4 & $65 \cdot 6$ & $67 \cdot 3$ & $2 \cdot 32$ \\
\hline Phylum Bacteroidetes & $34 \cdot 7^{\mathrm{a}}$ & $27 \cdot 2^{a, b}$ & $25 \cdot 5^{\mathrm{a}, \mathrm{b}}$ & $23 \cdot 0^{\mathrm{b}}$ & $2 \cdot 52$ \\
\hline Class Bacteroidetes & $34 \cdot 3^{a}$ & $26 \cdot 9^{a, b}$ & $25 \cdot 0^{\mathrm{a}, \mathrm{b}}$ & $22 \cdot 6^{\mathrm{b}}$ & $2 \cdot 52$ \\
\hline Phylum Proteobacteria & $5 \cdot 00$ & 3.70 & $5 \cdot 20$ & $5 \cdot 40$ & 0.38 \\
\hline Phylum Actinobacteria & 0.70 & $2 \cdot 30$ & 0.80 & 0.90 & 0.38 \\
\hline Phylum Unclassified Bacteria & 0.40 & 0.40 & 0.50 & 0.50 & 0.03 \\
\hline Phylum Tenericutes & $0 \cdot 10$ & $0 \cdot 10$ & $0 \cdot 10$ & 0.10 & 0.00 \\
\hline \multicolumn{6}{|l|}{ Day 16} \\
\hline Phylum Firmicutes & $55 \cdot 3^{b}$ & $58 \cdot 9^{a, b}$ & $58 \cdot 9^{a, b}$ & $68 \cdot 6^{a}$ & $2 \cdot 85$ \\
\hline Class Clostridia & $52 \cdot 6^{b}$ & $56 \cdot 8^{a, b}$ & $56 \cdot 5^{\mathrm{a}, \mathrm{b}}$ & $67 \cdot 1^{\mathrm{a}}$ & 3.09 \\
\hline Phylum Bacteroidetes & $38 \cdot 7^{\mathrm{a}}$ & $35 \cdot 9^{a, b}$ & $35 \cdot 5^{\mathrm{a}, \mathrm{b}}$ & $26 \cdot 2^{\mathrm{b}}$ & 2.72 \\
\hline Class Bacteroidetes & $38 \cdot 2^{\mathrm{a}}$ & $35 \cdot 5^{a, b}$ & $35 \cdot 1^{a, b}$ & $25 \cdot 7^{\mathrm{b}}$ & $2 \cdot 72$ \\
\hline Phylum Proteobacteria & $4 \cdot 70$ & $4 \cdot 40$ & $4 \cdot 60$ & $3 \cdot 80$ & 0.20 \\
\hline Phylum Actinobacteria & 0.70 & 0.60 & 0.60 & 0.80 & 0.05 \\
\hline Phylum Unclassified Bacteria & 0.50 & $0 \cdot 10$ & 0.30 & 0.50 & $0 \cdot 10$ \\
\hline Phylum Tenericutes & $0 \cdot 10$ & $0 \cdot 10$ & $0 \cdot 10$ & 0.10 & 0.00 \\
\hline
\end{tabular}

$\mathrm{NC}$, negative control; PC, positive control; WBf, wheat bran milled; WBc, wheat bran coarse.

${ }^{a, b}$ Mean values within a row with unlike superscript letters were significantly different $(P<0 \cdot 01)$. 
Table 4. Richness and diversity indices calculated from terminal restriction fragment length polymorphism data of the ileum digesta of nursery pigs challenged with enterotoxigenic Escherichia coli K88 on day 16 (Mean values with their standard errors, $n$ 9)

\begin{tabular}{|c|c|c|c|c|c|c|c|}
\hline \multirow[b]{2}{*}{ Sample } & \multirow[b]{2}{*}{ Indices ${ }^{*}$} & \multicolumn{4}{|c|}{ Diets } & \multirow[b]{2}{*}{ SEM } & \multirow[b]{2}{*}{$P$} \\
\hline & & NC & PC & WBf & WBC & & \\
\hline \multirow[t]{3}{*}{ Faeces } & $\begin{array}{c}\text { Richness } \\
\text { Chao2 }\end{array}$ & $218 \cdot 0^{a, b}$ & $244 \cdot 4^{a, b}$ & $263.0^{\mathrm{a}}$ & $202 \cdot 8^{b}$ & 37.78 & 0.038 \\
\hline & Diversity & & & & & & \\
\hline & Shannon & $3.7^{b}$ & $3 \cdot 3^{c}$ & $4 \cdot 1^{a}$ & $2 \cdot 8^{d}$ & 0.19 & $<0.001$ \\
\hline \multirow[t]{4}{*}{ Colon } & Richness & & & & & & \\
\hline & Chao2 & $171 \cdot 4^{\mathrm{b}}$ & $132 \cdot 0^{\mathrm{c}}$ & $196 \cdot 5^{\mathrm{a}}$ & $132 \cdot 1^{\mathrm{c}}$ & $17 \cdot 10$ & $<0.001$ \\
\hline & Diversity & & & & & & \\
\hline & Shannon & $4 \cdot 3^{b}$ & $4 \cdot 3^{b}$ & $4 \cdot 7^{\mathrm{a}}$ & $4 \cdot 2^{b}$ & 0.23 & $<0.001$ \\
\hline
\end{tabular}

can colonise the intestinal epithelium and produce diarrhoea $^{(27)}$. Animal, environmental or dietary factors may influence the manifestation of the disease. In the present experiment, feeding a diet supplemented with WBC and a diet supplemented with antibiotics reduced incidences of scours, compared with the NC diet. Diet WBc, but not PC, also reduced E. coli $\mathrm{K} 88$ in the ileum, compared to NC, as presented in a previous communication (counts were 4.7 , $4 \cdot 7,2 \cdot 2$ and $0 \cdot 7 \log$ colony-forming units/g of digesta for $\mathrm{NC}$, $\mathrm{PC}, \mathrm{WBf}$ and $\mathrm{WBc}$, respectively) ${ }^{(28)}$. In fact, both WBf and WBC diets reduced ileal populations of E. coli, compared to NC (counts were $6.3,6.3,4.9$ and 4.1 for NC, PC, WBf and WBc, respectively) ${ }^{(28)}$. This effect of WB on E. coli population could be related to the ability of WB to inhibit its adhesion to the intestinal receptors, diminishing the risk of diarrhoea as demonstrated for other fibre sources ${ }^{(29)}$. This is in good agreement with the in vitro results from our laboratory ${ }^{(30)}$, where E. coli K88 was shown to attach more to coarse particles of WB, compared to other fibre sources. However, the reduction of scours produced by the PC diet was not accompanied by reductions on $E$. coli populations. This observation has been repeatedly found ${ }^{(31)}$ and could be indicating a different mechanism of action for PC compared to the WBC diet or a non-causal relationship between the reduction of $E$. coli counts and diarrhoea scours.

A reduction in diarrhoea severity and pathogen counts has been previously described when different fibre sources were included in the diet ${ }^{(10,32,33)}$. Different mechanisms have been proposed to understand this preventive effect of fibre against diarrhoea. In previous studies ${ }^{(34)}$, we observed that WB with coarse particle size modifies the physico-chemical properties of digesta by increasing the water retention capacity (WRC). Mikkelsen et al. ${ }^{(35)}$ suggested that processes in the foregut, such as distribution of clorhidric acid within the stomach content, are favoured when a diet has a coarse structure and a higher WRC so that lower counts of enterobacteria reach the small intestine. This hypothesis could also explain the reduction in ETEC described previously. On the other hand, higher WRC has also been related to an enhancement of fibre fermentation and VFA concentration in the hindgut digesta ${ }^{(36)}$.
In the present study, the incorporation of a source of WB with a coarse particle increased the total VFA and acetate concentration in the colonic digesta. The increase in VFA production is proposed in itself as a positive factor on diarrhoea prognosis due to their function in fluid and electrolyte absorption ${ }^{(37)}$. The same fibre source, WB, lost this effect on fermentation when included in the diet in a finely milled form. Wrick et $a l .{ }^{(38)}$ described differences in the fermentation between coarse and finely milled WB and attributed these differences to the lower WRC of the ground WB.

Gut microbiota is a complex and not a well-characterised ecosystem. The introduction of phylogenetic analysis of $16 \mathrm{~S}$ rRNA increased the knowledge of microbiomes and $16 \mathrm{~S}$ rRNA cloning and sequencing has been applied to characterise the intestinal bacterial community in humans ${ }^{(39)}$ and pigs ${ }^{(40)}$ Several large clone libraries generated from human faecal samples and colonic biopsies show the dominance of two phyla: Firmicutes and Bacteroidetes ${ }^{(41,42)}$. Leser et al. ${ }^{(43)}$ and Bhandari et $a l .{ }^{(14)}$ found that the major divisions in the gut microbiome of pigs were also Firmicutes and Bacteroidetes. Both groups are fibre digesters and therefore they grow and produce VFA from dietary compounds, which escape digestion in the small intestine. The present study also shows that the WBc diet affected the microbial communities before and after an experimental ETEC infection. The administration of the WBc diet increased the presence of Firmicutes associated with the previously described changes in the incidences of diarrhoea and colon fermentation. A possible explanation for this difference is given by Walker et al. ${ }^{(44)}$ who reported that the particle-associated and planctonic communities in human faecal material differ significantly, with a higher proportion of Firmicutes associated with particles and a higher proportion of Bacteroidetes associated with the liquid fraction. However, a question to resolve is whether this diet-induced microbial change can be causally related to the health status of the host.

A higher Firmicutes:Bacteroidetes ratio promoted by fibre has been previously reported. Middelbos et al. $^{(45)}$ reported an increase in the Firmicutes phylum in dogs using 454 pyrosequencing when sugarbeet pulp was included in the diet 
compared with a non-fibre diet. Whether this increase in the Firmicutes:Bacteroidetes ratio is related to a decrease in diarrhoea might be discussed. Mulder et al. ${ }^{(46)}$ used a pig model to study if the early microbial colonisation of the gut reduces the incidence of infectious, inflammatory and autoimmune diseases. They reported that pigs housed in a natural outdoor environment showed a dominance of Firmicutes, whereas animals housed in a hygienic indoor environment had higher numbers of potentially pathogenic phylotypes in the GIT. They concluded that there was a strong negative correlation between the abundance of Firmicutes and pathogenic bacterial populations in the intestine. In humans, Mariat et $a l .{ }^{(47)}$ have suggested that infants and the elderly, who are more sensitive to pathogens, present ten times lower Firmicutes:Bacteroidetes ratios, compared to healthy adults. Stecher et $a l .{ }^{(48)}$ have recently proposed that an abundance of closely related species can predict susceptibility to intestinal colonisation by pathogenic or commensal bacteria. E. coli is part of the Proteobacteria phylum and Gammaproteobacteria class and so not genetically close to Firmicutes or Bacteroidetes. Whether Firmicutes could create a more hostile environment for pathogens needs to be clarified. This effect, together with the changes in the physico-chemical properties of digesta and the enhancement of the fermentative capacity in the GIT, may make the gut more resistant to infections.

Why PC reduced diarrhoea but did not show any of the effects shown by WBC deserves to be investigated. Only microbial diversity and richness showed some coincidences but not very consistently. However, this observation is repeatedly seen in the literature. Tajima et al. ${ }^{(49)}$ found a reduction on the bacterial diversity in the caecum digesta when an antibiotic was included in the post-weaning piglet diet. Similarly, Högberg et al. ${ }^{(50)}$ and Castillo et al. ${ }^{(51)}$ also found a reduction on the diversity index when WB as coarse particle size was incorporated in the diet, suggesting an adaptation of the gut microbiota to fibrous diets. New methods to analyse microbial communities are bringing some light to the complex intestinal ecosystem. More studies using new analysis methods should be carried out in the future in order to increase our knowledge on 'healthy' and 'unhealthy' intestinal microbial communities and how these may be manipulated by dietary interventions.

\section{Conclusion}

Based on the results of the present work, we conclude that the composition of the pig gut microbial community can be modified by the inclusion of a relatively small amount of WB in the diet, being the physical presentation of the fibre a determinant of that difference. How this change relates to diarrhoea occurrence needs to be further studied.

\section{Acknowledgements}

The authors thank the Ministerio de Educación, Cultura y Deporte, Spain for research fellowships. The authors also thank the staff from the University of Manitoba's T.K. Cheung Centre for Animal Science Research for their service and assistance during the present experiment. The following are the contributions of each author to this study: F. M. participated in the research and in the writing of the manuscript. E. G. M. participated in the writing of the manuscript. J. F P. participated in the research and in the writing of the manuscript. C. M. N. participated in the research and in the writing of the manuscript. All authors declare that there are no conflicts of interest.

\section{References}

1. Cummings JH \& Englyst HN (1987) Fermentation in the human large intestine and the available substrates. $\mathrm{Am} \mathrm{J}$ Clin Nutr 45, 1243S-1255S.

2. Guarner F \& Malagelada JR (2003) Gut flora in health and disease. Lancet 361, 512-519.

3. Hooper LV, Wong MH, Thelin A, et al. (2001) Molecular analysis of commensal host-microbial relationships in the intestine. Science 291, 881-884.

4. Peterson DA, McNultry NP, Guruge JL, et al. (2007) IgA response to symbiotic bacteria as a mediator of gut homeostasis. Cell Host Microbe 2, 328-339.

5. Qadri F, Svennerholm AM, Faruque AS, et al. (2005) Enterotoxigenic Escherichia coli in developing countries: epidemiology, microbiology, clinical features, treatment, and prevention. Clin Microbiol Rev 18, 465-483.

6. Duijts L, Jaddoe VWV, Hofman A, et al. (2010) Prolonged and exclusive breastfeeding reduces the risk of infectious diseases in infancy. Pediatrics 126, e18-e25.

7. Lallès JP, Bosi P, Smidt H, et al. (2007) Weaning - a challenge to gut physiologists. Livest Sci 108, 82-93.

8. World Health Organization (2004) Clinical Management of Acute Diarrhoea. New York, NY: WHO.

9. Kim JC, Mullan BP, Hampson DJ, et al. (2008) Addition of oat hulls to an extruded rice-based diet for weaner pigs ameliorates the incidence of diarrhoea and reduces indices of protein fermentation in the gastrointestinal tract. $\mathrm{Br} \mathrm{J}$ Nutr 99, 1217-1225.

10. Mateos GG, Martin F, Latorre MA, et al. (2006) Inclusion of oat hulls in diets for young pigs based on cooked maize or cooked rice. Anim Sci 82, 57-63.

11. Molist F, Ywazaki M, Gómez de Segura A, et al. (2010) Administration of loperamide and addition of wheat bran to the diets of weaner pigs decrease the incidence of diarrhoea and enhance their gut maturation. Br J Nutr 103, $879-885$.

12. Canadian Council on Animal Care (1993) Guide to Care and Use of Experimental Animals [ED Olfert, BM Cross and AA McWilliam, editors]. Ottawa, ON: Canadian Council on Animal Care.

13. National Research Council (1998) Nutrient Requirements for Swine. Washington, DC: National Academy Press.

14. Bhandari SK, Xu B, Nyachoti CM, et al. (2008) Evaluation of alternatives to antibiotics using an Escherichia coli $\mathrm{K}^{+} 8^{+}$ model of piglet diarrhea: effects on gut microbial ecology. J Anim Sci 86, 836-847.

15. Marquardt RR, Jin LZ, Kim JW, et al. (1999) Passive protective effect of egg-yolk antibodies against enterotoxigenic Escherichia coli $\mathrm{K}^{+} 8^{+}$infection in neonatal and earlyweaned piglets. FEMS Immunol Med Microbiol 23, 283-288.

16. Association of Official Analytical Chemists (1995) Official Methods of Analysis. Arlington, VA: AOAC.

17. Krause DO, Easter RA, White BA, et al. (1995) Effect of weaning diet on the ecology of adherent lactobacilli in the gastrointestinal tract of the pig. J Anim Sci 73, 2347-2354. 
18. Erwin ES, Marco GJ \& Emery M (1961) Volatile fatty acids analysis of blood and rumen fluid by gas chromatography. J Dairy Sci 44, 1768-1771

19. Novozamsky I, Van Eck R, Showenburg JCH, et al. (1974) Total nitrogen determination in plant material by means of the indole-phenol blue method. Neth J Agri Sci 22, 3-5.

20. Abdo Z, Schuette UM, Bent SJ, et al. (2006) Statistical methods for characterizing diversity of microbial communities by analysis of terminal restriction fragment length polymorphisms of $16 \mathrm{~S}$ rRNA genes. Environ Microbiol 8, 929-938.

21. Lane DJ (1991) 16S/23S rRNA sequencing. In Nucleic Acid Techniques in Bacterial Systematics, pp. 115-175 [E Stackebrandt and M Goodfellow, editors]. New York, NY: John Wiley and Sons.

22. Shyu C, Soule T, Bent SJ, et al. (2007) MiCA: a web-based tool for the analysis of microbial communities based on terminal restriction fragment length polymorphisms of $16 \mathrm{~S}$ and $18 S$ rRNA genes. Microb Ecol 53, 562-570.

23. Kent AD, Smith DJ, Benson BJ, et al. (2003) A web-based phylogenetic assignment tool for analysis of terminal restriction fragment length polymorphism profiles of microbial communities. Appl Environ Microbiol 69, 6768-6776.

24. Cole JR, Chai B, Farris RJ, et al. (2005) The Ribosomal Database Project (RDP-II): sequences and tools for highthroughput rRNA analysis. Nucleic Acid Res 33, D294-D296.

25. Colwell RK (2005) EstimateS: Statistical Estimation of Species Richness and Shared Species from Samples, version 7.5 . User's Guide. http://purl.oclc.org/estimates

26. SAS Inc. (1999) SAS ${ }^{\circledR}$ User's Guide: Statistics. Cary, NC: SAS, Inc.

27. Anderson MJ, Whitehead JS \& Kim YS (1980) Interaction of Escherichia coli K88 antigen with porcine intestinal brush border membranes. Infect Immun 29, 897-901.

28. Molist F, Gómez de Segura A, Pérez JF, et al. (2010) Effect of wheat bran on the health and performance of weaned pigs challenged with Escherichia coli $\mathrm{K}^{+} 8^{+}$. Liv Sci 133, 214-217.

29. Kiers JL, Nout MJR, Rombouts FM, et al. (2002) Inhibition of adhesion of enterotoxigenic Escherichia coli K88 by soya bean tempe. Lett Appl Microbiol 35, 311-315.

30. Molist F, Hermes RG, Gómez de Segura A, et al. (2011) Effect and interaction between wheat bran and zinc oxide on productive performance and intestinal health in post-weaning piglets. Br J Nutr 105, 1592-1600.

31. Krause DO, Bhandari SK, House JD, et al. (2010) Response of nursery pigs to a symbiotic preparation of starch and an anti-Escherichia coli K88 probiotic. Appl Environ Microbiol 76, 8192-8200.

32. Wellock IJ, Houdijk JGM \& Kyriazakis I (2007) Effect of dietary non-starch polysaccharide solubility and inclusion level on gut health and the risk of post-weaning enteric disorders in newly weaned piglets. Liv Sci 108, 186-189.

33. Bikker P, Dirkzwager A, Fledderus J, et al. (2006) The effect of dietary protein and fermentable carbohydrates levels on growth performance and intestinal characteristics in newly weaned piglets. J Anim Sci 84, 3337-3345.

34. Molist F, Gómez de Segura A, Gasa J, et al. (2009) Effects of the insoluble and soluble dietary fibre on the physicochemical properties of digesta and the microbial activity in early weaned piglets. Anim Feed Sci Technol 149, 346-353.

35. Mikkelsen LL, Naughton PJ, Hedemann MS, et al. (2004) Effects of physical properties of feed on microbial ecology and survival of Salmonella enterica serovar Typhimurium in the pig gastrointestinal tract. Appl Environ Microbiol 70 , 3485-3492.

36. Anguita M, Canibe N, Pérez JF, et al. (2006) Influence of the amount of dietary fibre on the available energy from hindgut fermentation in growing pigs: use of cannulated pigs and in vitro fermentation. J Anim Sci 84, 2766-2778.

37. Pizarro D, Posada G, Sandi L, et al. (1991) Rice-based oral electrolyte solutions for the management of infantile diarrhea. $N$ Engl J Med 324, 517-521.

38. Wrick KL, Robertson JB, Van Soest PJ, et al. (1983) The influence of dietary fibre source on human intestinal transit and stool output. J Nutr 113, 1464-1479.

39. Suau A, Bonnet R, Sutren M, et al. (1999) Direct analysis of genes encoding 16S rRNA from complex communities reveals many novel molecular species within the human gut. Appl Environ Microbiol 65, 4799-4807.

40. Ludwig W, Bauer SH, Bauer M, et al. (1997) Detection and in situ identification of representatives of a widely distributed new bacterial phylum. FEMS Microbiol Lett 153, 181-190.

41. Rakoff-Nahoum S, Paglino J, Eslami-Varzaneh F, et al. (2004) Recognition of commensal microflora by toll-like receptors is required for intestinal homeostasis. Cell 118, 229-241.

42. Frank DN, St Amand AL, Feldman RA, et al. (2007) Molecular-phylogenetic characterization of microbial community imbalances in human inflammatory bowel diseases. Proc Natl Acad Sci U S A 104, 13780-13785.

43. Leser TD, Amenuvor JZ, Jensen TK, et al. (2002) Cultureindependent analysis of gut bacteria: the pig gastrointestinal tract microbiota revisited. Appl Environ Microbiol 68, 673-690.

44. Walker AW, Duncan SH, Harmsen HJM, et al. (2008) The species composition of the human intestinal microbiota differs between particle-associated and liquid phase communities. Environ Microbiol 10, 3275-3283.

45. Middelbos IS, Vester Boler BM, Qu A, et al. (2010) Phylogenetic characterization of fecal microbial communities of dogs fed diets with or without fibre using 454 pyrosequencing. PLoS One 3, e9768.

46. Mulder IE, Schmidt B, Stokes CR, et al. (2009) Environmentally-acquired bacteria influence microbial diversity and natural innate immune response at gut surfaces. $B M C$ Biol 7, 1-20.

47. Mariat D, Firmesse O, Levenez F, et al. (2009) The Firmicutes/Bacteroidetes ratio of the human microbiota changes with age. BMC Microbiol 9, 123.

48. Stecher B, Chaffron S, Kappeli R, et al. (2010) Like will to like: abundances of closely related species can predict susceptibility to intestinal colonization by pathogenic and commensal bacteria. PLoS Pathogens 6, e1000711.

49. Tajima K, Ohmori H, Aminov RI, et al. (2010) Fermented liquid feed enhances bacetrial diversity in piglet intestine. Anaerobe 16, 6-11.

50. Högberg A, Lindberg JE, Leser T, et al. (2004) Influence of cereal non starch polysaccharides on ileo-caecal and rectal microbial populations in growing pigs. Acta Vet Scand $\mathbf{4 5}$ 87-98.

51. Castillo M, Skene G, Roca M, et al. (2007) Application of $16 \mathrm{~S}$ rRNA gene-targetted fluorescence in situ hybridization and restriction fragment length polymorphism to study porcine microbiota along the gastrointestinal tract in response to different sources of dietary fibre. FEMS Microbiol Ecol 59 138-146. 